\title{
The study of the kinetics of formation of gaseous products during thermochemical conversion of woody biomass
}

\author{
Alexander Kozlov* \\ Kutateladze Institute of Thermophysics, Siberian Branch of the Russian Academy of Sciences, Academician \\ Lavrentyev Avenue 1, Novosibirsk, 630090, Russia
}

\begin{abstract}
The article shows the effect of the stage of internal combustion of biomass (pine sawdust) with insufficient and excessive heat supply. Thermochemical conversion of pine sawdust was carried out first in a dynamic mode to different temperatures of $280,320,360,440$ and $440{ }^{\circ} \mathrm{C}$, and then transferred to the isothermal mode for 1 hour. As a result, the following results were obtained: 1) Hydrogen does not form when heated to $280^{\circ} \mathrm{C}$; it is formed in small quantities at $320^{\circ} \mathrm{C}$. From a temperature of $360^{\circ} \mathrm{C}$ and higher, the formation of hydrogen becomes significant. You can also select two modes of education, which is especially noticeable at a temperature of $440{ }^{\circ}$ C. 2) In the cases of $\mathrm{CH}_{4}, \mathrm{H}_{2} \mathrm{O}, \mathrm{CO}$ and $\mathrm{CO}_{2}$, three stages of formation can be distinguished: low-temperature, medium-temperature and high-temperature. For each selected stage, the corresponding kinetic coefficients were calculated.
\end{abstract}

\section{Introduction}

A common way to study the mechanisms and kinetics of thermochemical conversion of woody biomass is thermal analysis. The condition for using thermal analysis is that after some time after the start of heating a regular mode is established in which the heating rate of the sample is equal to the heating rate of the external environment, which provides the simplest connections between the characteristics of thermoanalytical curves and various thermal and kinetic quantities. With properly selected conditions for conducting thermal analysis, predominantly the kinetic mode of combustion is established, and the kinetic kinetic coefficients can be determined directly from experimental data. [1].

Nowadays, synchronous thermal analysis (CTA) is available, which combines thermogravimetric (TG), differential thermal analysis (DTA) or differential scanning calorimetry (DSC) within a single installation, which allows you to directly compare the measurements of TG and DSC / DTA, while eliminating the influence of the inhomogeneity of the material, measurement conditions.

In addition, the installation can be supplemented with devices for physico-chemical analysis of gaseous compounds released as a result of decomposition of samples. The main condition for such an analysis should be the technical possibility of simultaneous fixation of thermoanalytical measurements and recording of evolved gases. Only compliance with this condition will allow us to correctly interpret the results [2]. Such methods are FT-IR spectroscopy [3], chromatographic analysis methods [4], optical spectroscopy [5], and mass spectrometry [6].
Analysis of the composition of the gas mixture formed during the combustion of fuels made it possible to supplement thermoanalytical studies with information on the formation of gas products depending on external conditions, including determining the kinetics of their formation.

Thus, the aim of the work is to determine the mechanisms and kinetics of the formation of gaseous compounds formed during the thermochemical conversion of woody biomass.

\section{The methodic experimental data processing}

\subsection{Methods of research}

Thermal conversion studies of wood biomass were performed using an integrated complex simultaneous thermal analysis (STA449F1) coupled with a quadrupole mass spectrometer (QMS403C), produced by NETZSCH.

Samples of pine sawdust weighing 13-17 mg were placed in a corundum crucible in the form of a flat plate. The flat shape of the crucible promotes uniform access of the oxidizer to the fuel particles. Samples were heated in an inert atmosphere (argon) from $35^{\circ} \mathrm{C}$ to isothermal holding temperature $\left(280,320,360,400\right.$ and $\left.440{ }^{\circ} \mathrm{C}\right)$ at a rate of $20{ }^{\circ} \mathrm{C} / \mathrm{min}$. When the temperature reached an isothermal holding, the heating was stopped and held for 1 hour. The gaseous products formed as a result of thermochemical conversion of coal were recorded in the mass range from 1 to 200 with ionization by electron impact at $70 \mathrm{eV}$. 
The proximate and ultimate analysis of pine sawdust are given in table 1 .

Table 1. The proximate and ultimate analysis of pine sawdust.

\begin{tabular}{|c|c|c|c|c|c|c|c|c|}
\hline \multirow[t]{2}{*}{$\begin{array}{l}\text { Woody } \\
\text { biomass }\end{array}$} & \multicolumn{3}{|c|}{$\begin{array}{c}\text { Proximate analysis } \\
\text { (as rec'd basis, \%) }\end{array}$} & \multicolumn{5}{|c|}{$\begin{array}{l}\text { Ultimate analysis } \\
\text { (daf basis. wt.\%) }\end{array}$} \\
\hline & W VM & $\mathrm{FC}$ & $\mathrm{A}$ & $\mathrm{C}$ & $\mathrm{H}$ & $\mathrm{O}$ & $\mathrm{N}$ & $\mathrm{S}$ \\
\hline Pine & 80.1 & 15.1 & 1.1 & 54.3 & 5.2 & 40.0 & 0.4 & 0.0 \\
\hline
\end{tabular}

*W - moisture, $\mathrm{VM}$ - volatile matter, $\mathrm{FC}$ - fixed carbon, A - ash.

Figure 1 shows the thermogravimetric curves of weight loss of the studied samples.

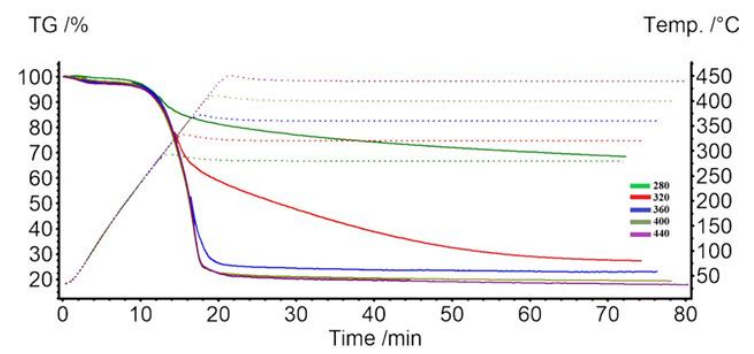

Fig.1. Thermogravimetric curves of thermochemical conversion of wood.

Analysis of fig. 1 shows that, starting from $360{ }^{\circ} \mathrm{C}$, the conversion process takes place almost to the end, i.e. the heat supplied to the sample is sufficient to maintain a chain reaction of internal combustion, due to the presence of a significant amount of oxygen in the composition of woody biomass. At lower temperatures of 280 and $320{ }^{\circ} \mathrm{C}$, the heat supplied is not enough for complete conversion of wood, and at higher temperatures of 400 and $440{ }^{\circ} \mathrm{C}$, it comes in abundance.

\subsection{Kinetics model}

The kinetics of the formation of gaseous compounds according to mass spectrometry can be calculated by the Arrhenius equation in the approximation of a one-stage first-order reaction:

$$
\frac{d I_{j}}{d t}=-A e^{\frac{-E a}{R T}} I_{j}
$$

Kinetic coefficients can be determined by dividing the variables and linearizing the equation (1).

$$
\begin{aligned}
& \frac{d I_{j}}{I_{j} d t}=-A e^{\frac{-E a}{R T}} \\
& -\frac{d \ln I_{j}}{d T}=A e^{\frac{-E a}{R T}} \\
& \ln \left(-\frac{d \ln I_{j}}{d T}\right)=\ln A-\frac{E_{a}}{R T}
\end{aligned}
$$

where $A$ - pre-exponential factor, $\mathrm{s}^{-1} ; E a$ - activation energy, $\mathrm{kJ} / \mathrm{mole} ; R$ - universal gas constant, 8.314 $\mathrm{J} /$ moleK; T - temperature, $\mathrm{K} ; I_{j}$ - ion current of the $j^{\text {th }}$ component, j- $\mathrm{CO}, \mathrm{CO}_{2}, \mathrm{CH}_{4}, \mathrm{H}_{2}, \mathrm{H}_{2} \mathrm{O}$.

\section{Results and discussion}

In fig. 2 shows the mass spectrometric curves of the main gaseous substances formed during the thermochemical conversion of pine sawdust.

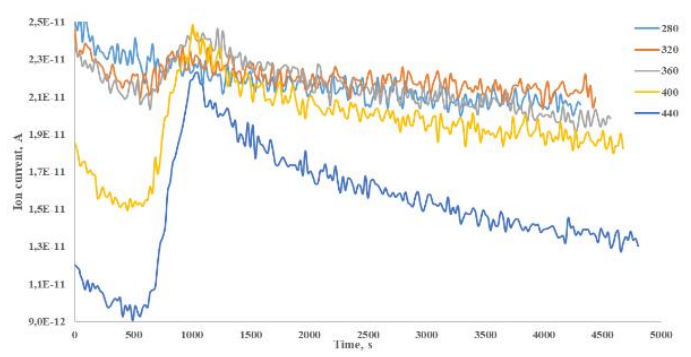

$\mathrm{H}_{2}$
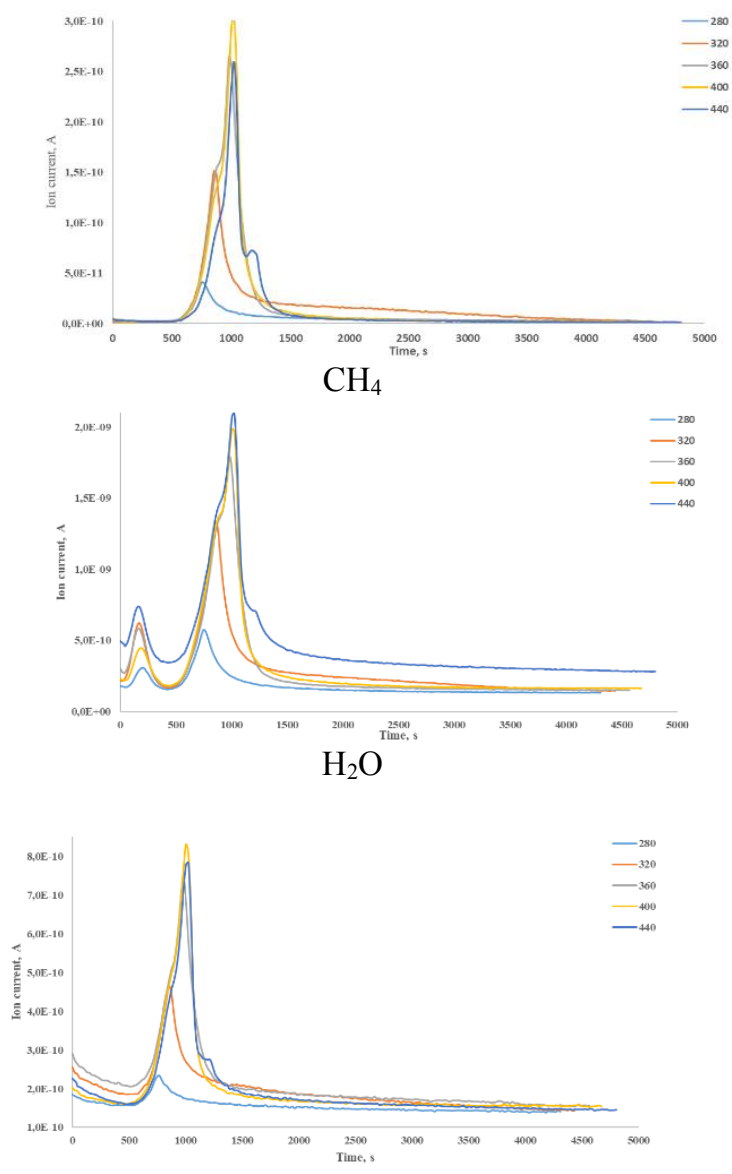

$\mathrm{CO}$

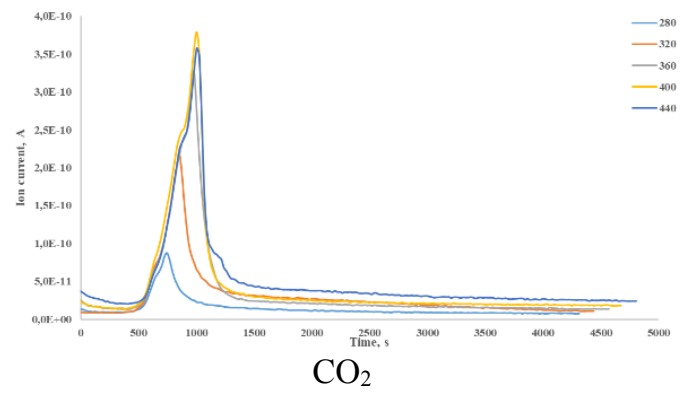

Fig. 2. Mass spectrometry curves of compounds formed during thermochemical conversion of pine sawdust.

Analysis of fig. 2 shows the following:

1. $\mathrm{H}_{2}$ does not form when heated to $280{ }^{\circ} \mathrm{C}$; it is formed in small quantities at $320^{\circ} \mathrm{C}$. From a temperature 
of $360{ }^{\circ} \mathrm{C}$ and higher, the formation of hydrogen becomes significant. You can also select two modes of education, which is especially noticeable at a temperature of $440{ }^{\circ} \mathrm{C}$.

2. In the cases of $\mathrm{CH}_{4}, \mathrm{H}_{2} \mathrm{O}, \mathrm{CO}$, and $\mathrm{CO}_{2}$, three stages of formation can be distinguished: lowtemperature, medium-temperature, and hightemperature. It is worth noting that the initial peak in water is due to the drying of wood and this stage is identical for all the samples studied.

Further processing of the calculated curves of the formation of individual substances in relation to the construction of the dependences $\ln (\mathrm{dI} / \mathrm{dt})-1000 / \mathrm{T}$ in Arrhenius coordinates allows us to determine the activation energy and the pre-exponential factor (Fig. 3).

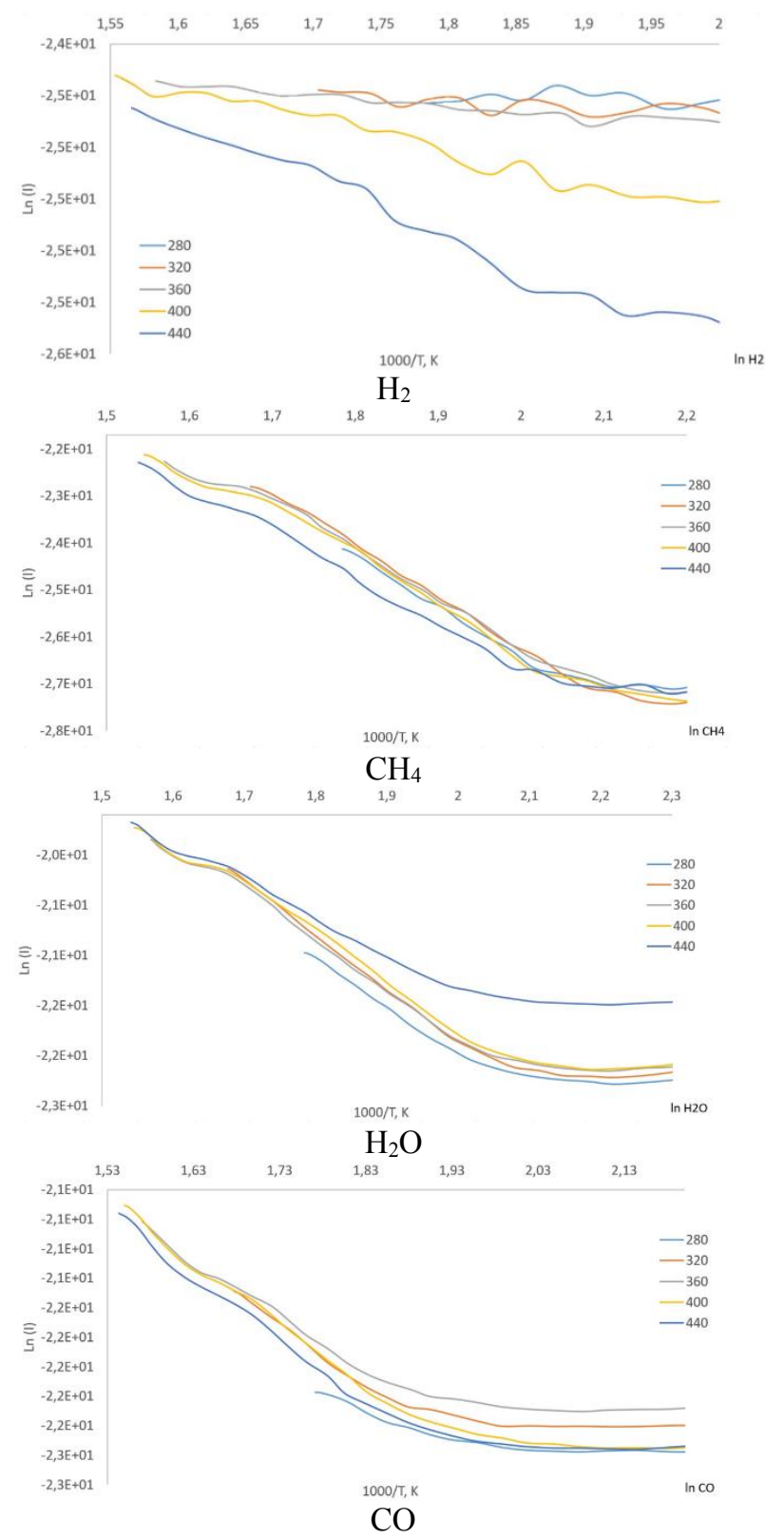

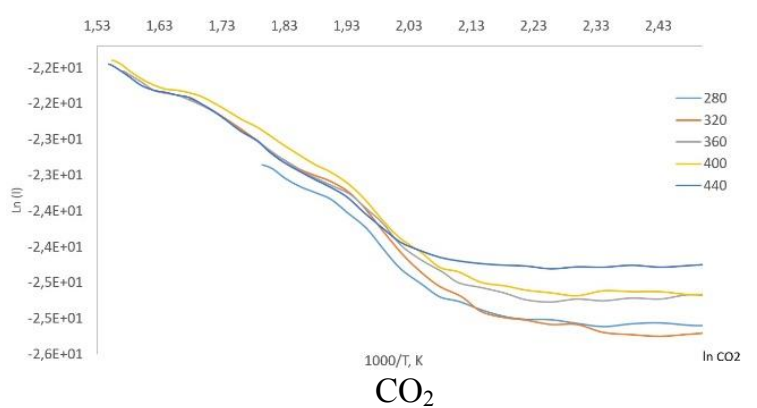

Fig. 3. Kinetic curves of formation of gaseous products during thermochemical wood.

Table 2 shows the calculated values of the kinetic coefficients of formation of gaseous products during thermochemical conversion of wood.

Table 2. Kinetic coefficients for the formation of gaseous products.

\begin{tabular}{cccc}
\hline Compound & Stage number & $\mathrm{Ea}, \mathrm{kJ} / \mathrm{mole}$ & $\mathrm{A}, \mathrm{s}^{-1}$ \\
\hline \multirow{2}{*}{$\mathrm{CH}_{4}$} & 1 & 91.5 & $2.35 \mathrm{e}-11$ \\
& 2 & 71.2 & $7.74 \mathrm{e}-11$ \\
& 3 & 83.4 & $1.33 \mathrm{e}-10$ \\
\hline \multirow{2}{*}{$\mathrm{H}_{2} \mathrm{O}$} & 1 & 25.5 & $2.39 \mathrm{e}-10$ \\
& 2 & 34.2 & $7.18 \mathrm{e}-10$ \\
& 3 & 31.7 & $5.63 \mathrm{e}-10$ \\
\hline \multirow{2}{*}{$\mathrm{CO}$} & 1 & 7.84 & $1.95 \mathrm{e}-11$ \\
& 2 & 52.9 & $2.65 \mathrm{e}-10$ \\
& 3 & 144.1 & $2.20 \mathrm{e}-10$ \\
\hline \multirow{2}{*}{$\mathrm{CO}_{2}$} & 1 & 60.2 & $3.41 \mathrm{e}-11$ \\
& 2 & 45.1 & $1.62 \mathrm{e}-10$ \\
$\mathrm{H}_{2}$ & 3 & 40.2 & $9.17 \mathrm{e}-11$ \\
\hline
\end{tabular}

\section{Conclusion}

As a result of the work, the following results were obtained:

1) Hydrogen does not form when heated to $280^{\circ} \mathrm{C}$; it is formed in small quantities at $320^{\circ} \mathrm{C}$. From a temperature of $360^{\circ} \mathrm{C}$ and higher, the formation of hydrogen becomes significant. You can also select two modes of education, which is especially noticeable at a temperature of $440^{\circ} \mathrm{C}$.

2) In the cases of $\mathrm{CH}_{4}, \mathrm{H}_{2} \mathrm{O}, \mathrm{CO}$ and $\mathrm{CO}_{2}$, three stages of formation can be distinguished - lowtemperature, medium-temperature and high-temperature.

3) For each selected stage, the corresponding kinetic coefficients were calculated.

\section{References}

1. Principles and practice / ed. by M.E. Brown // Handbook of thermal analysis and calorimetry / series ed. by P.K. Gallagher. - Netherlands, Amsterdam: Elsevier Science, 543 p, (1998)

2. E. Kaiserberger, E. Post Thermochimica Acta, Practical aspects for the coupling of gas analytical methods with thermal-analysis instruments V. 295, P. 73-93, (1997)

3. C.G. Mothe, B.C. de Castro, M.G. Mothe J Therm Anal Calorim, Characterization by TG/DTG/DSC and 
FTIR of frying and fish oil residues to obtain biodiesel V. 106, №. 3, P. 811-817, (2011)

4. M. Ischia, C. Perazzolli, R. Dal Maschio, R. Campostrini J Therm Anal Calorim, Pyrolysis study of sewage sladge by $T G-M S$ and $T G-G G-M S$ coupled analyses V. 87, №. 2, P. 567-574, (2007)

5. C. Slough, S. Aubuchon Technical Program of the 39th North American Thermal Analysis Society Conference (August 7-10, 2011 - Des Moines, Iowa) [Электрон. pecypc]. - Des Moines: NATAS, 2011. Электрон. опт. диск (CD-ROM), The Integration of Optical Spectroscopy with Thermal Analysis Techniques, (2011).

6. J. C. May, A.V. Del Crosso, R. M. Wheeler, N. M. Etz J Therm Anal Calorim, TG/MS capillary interface V. 49, №. 2, P. 929-936, (1997)

\section{Acknowledgements}

The research was performed at Kutateladze Institute of Thermophysics SB RAS under the support of Russian Science Foundation (Grant № 15-19-10025). 